\title{
Intercomparison of atmospheric water vapor soundings from the differential absorption lidar (DIAL) and the solar FTIR system on Mt. Zugspitze
}

\author{
H. Vogelmann, R. Sussmann, T. Trickl, and T. Borsdorff \\ Karlsruhe Institute of Technology (KIT), IMK-IFU, Garmisch-Partenkirchen, Germany \\ Received: 10 November 2010 - Published in Atmos. Meas. Tech. Discuss.: 2 December 2010 \\ Revised: 13 April 2011 - Accepted: 28 April 2011 - Published: 9 May 2011
}

\begin{abstract}
We present an intercomparison of three years of measurements of integrated water vapor (IWV) performed by the mid-infrared solar FTIR (Fourier Transform Infra-Red) instrument on the summit of Mt. Zugspitze (2964 ma.s.l.) and by the nearby near-infrared differential absorption lidar (DIAL) at the Schneefernerhaus research station ( $2675 \mathrm{~m}$ a.s.l.). The solar FTIR was shown to be one of the most accurate and precise IWV sounders in recent work (Sussmann et al., 2009) and is taken as the reference here. By calculating the FTIR-DIAL correlation (22 min coincidence interval, 15 min integration time) we derive an almost ideal slope of 0.996 (10), a correlation coefficient of $R=0.99$, an IWV intercept of $-0.039(42) \mathrm{mm}(-1.2 \%$ of the mean), and a bias of -0.052 (26) $\mathrm{mm}(-1.6 \%$ of the mean) from the scatter plot. By selecting a subset of coincidences with an optimum temporal and spatial matching between DIAL and FTIR, we obtain a conservative estimate of the precision of the DIAL in measuring IWV which is better than $0.1 \mathrm{~mm}$ (3.2\% of the mean). We found that for a temporal coincidence interval of $22 \mathrm{~min}$ the difference in IWV measured by these two systems is dominated by the volume mismatch (horizontal distance: $680 \mathrm{~m}$ ). The outcome from this paper is twofold: (1) the IWV soundings by FTIR and DIAL agree very well in spite of the differing wavelength regions with different spectroscopic line parameters and retrieval algorithms used. (2) In order to derive an estimate of the precision of state-of-the-art IWV sounders from intercomparison experiments, it is necessary to use a temporal matching on time scales shorter than $10 \mathrm{~min}$ and a spatial matching on the $100-\mathrm{m}$ scale.
\end{abstract}

Correspondence to: $\mathrm{H}$. Vogelmann (hannes.vogelmann@kit.edu)

\section{Introduction}

Water vapor is a key component of the atmosphere (Kiehl and Trenberth, 1997; Trenberth et al., 2007). Its distribution plays a major role for both meteorological phenomena and climate. One of the big challenges in climate research is to identify long term changes of the water vapor distribution, especially in the upper troposphere and lower stratosphere (UT/LS). In this altitude region, small changes of the water vapor concentration can result in a heavy impact on the radiative balance (Harries, 1997). Consequently, highly accurate sounding techniques are needed.

It has been shown in a series of papers that the FTIR technique is capable of providing information about the vertical distribution of water vapor (e.g. Schneider and Hase, 2009 , and references therein). For measuring integrated water vapor (IWV) solar Fourier-transform infrared spectrometry (FTIR) was recently shown to be one of the most accurate and precise ground-based remote sensing techniques (Sussmann et al., 2009) and this has been confirmed by follow-on intercomparison studies (Pałm et al., 2010; Schneider et al., 2010): Table 1 in Sussmann et al. (2009) shows that FTIR is comparable with or better than other state-of-the-art IWV sounding techniques, such as GPS, microwave radiometers, Raman lidars, or sun photometers (e.g. Morland et al., 2006; Fiorucci et al., 2008). The precision of FTIR for IWV was estimated to be better than $0.05 \mathrm{~mm}(2.2 \%)$, and perfect matching to radiosonde response characteristics (scatter plot with slope $\equiv 1$ ) could be achieved by applying a dedicated Tikhonov-based spectral inversion scheme to the FTIR data; this retrieval was utilized for a harmonized study of the decadal trends in IWV above the Zugspitze and Jungfraujoch FTIR stations (Sussmann et al., 2009).

Published by Copernicus Publications on behalf of the European Geosciences Union. 
Profiling water vapor throughout the troposphere with a differential absorption lidar (DIAL) still is under development due to the technically demanding requirement of using tunable narrow-band high-power laser light in the nearinfrared spectral domain. While free tropospheric profiling of water vapor has been demonstrated by airborne DIAL systems for many years (Ehret et al., 1993; Browell et al., 1996; Bruneau et al., 2001), the Zugspitze DIAL is, to our knowledge, the first and only ground based water-vapor DIAL covering the entire free troposphere (Vogelmann and Trickl, 2008).

Large discrepancies between different sets of spectral line parameters have been reduced by recent investigations (Ponsardin and Browell, 1997; Schermaul et al., 2001; Tolchenov and Tennyson, 2008; Rothman et al., 2009). The LUAMI (Lindenberg Upper Air Methods Intercomparison) campaign in which the Zugspitze DIAL participated stimulated further efforts for refining the retrieval (Wirth et al., 2009). Thus, the intercomparison of DIAL-derived IWV with a validated, highly accurate, and precise method like FTIR is an important step for verifying the DIAL spectroscopic parameters employed and is the goal of this paper. At the same time, this intercomparison provides an estimate of the precision attainable by the DIAL measurements for IWV. Section 2 will present the set up for the intercomparison experiment which is based on the Zugspitze FTIR system installed in 1995 on the Zugspitze summit at $47.42^{\circ} \mathrm{N}, 10.98^{\circ} \mathrm{E}$, 2964 m a.s.l. (Sussmann and Schäfer, 1997) and the DIAL which began its routine operation at the nearby Schneefernerhaus in 2007 ( $680 \mathrm{~m}$ southwest of the summit, $2675 \mathrm{~m}$ a.s.l.). Section 3 will describe the intercomparison data set comprising three years of coincident measurements which will be utilized in Sect. 3.1 to derive the bias, intercept, and slope from a scatter plot. Section 3.2 will show the optimization of the spatio-temporal coincidence criteria as a basis for the subsequent estimation of the precision of the DIAL. Section 4 will give the summary and an outlook.

\section{Instruments and intercomparison setup}

\subsection{Zugspitze solar FTIR system}

Solar absorption FTIR spectrometry uses the direct radiation from the sun in the mid-infrared range as the light source. The FTIR provides total columns of a variety of atmospheric trace gases. Additionally, information on the vertical distribution of trace gases can be derived (typically 1-4 degrees of freedom) from the changes of the infrared spectral line shapes with pressure and temperature. Due to its principle of operation, the solar FTIR measures slant columns/profiles pointing towards the actual position of the sun. The FTIR instrument located on the summit of Mt. Zugspitze is based on a Bruker IFS125HR interferometer and is described in detail by Sussmann and Schäfer (1997) (Table 1). The retrieval
Table 1. Specifications of the FTIR and the DIAL on Mt. Zugspitze.

\begin{tabular}{lll} 
& FTIR & DIAL \\
\hline geographical & E $10^{\circ} 59^{\prime} 8.7^{\prime \prime}$ & E $10^{\circ} 58^{\prime} 46.8^{\prime \prime}$ \\
coordinates & $\mathrm{N} 47^{\circ} 25^{\prime} 15.6^{\prime \prime}$ & $\mathrm{N} 47^{\circ} 25^{\prime} 0^{\prime \prime}$ \\
altitude a.s.1. & $2964 \mathrm{~m}$ & $2675 \mathrm{~m}$ \\
vertical range a.s.1. & above $2.96 \mathrm{~km}$ & $2.95 \mathrm{~km}-12 \mathrm{~km}$ \\
typ. integration time & $15-20 \mathrm{~min}$ & $14-16 \mathrm{~min}$ \\
wavenumbers $\left[\mathrm{cm}^{-1}\right]$ & microwindows & $v_{\text {on }}$ \\
& $839.5-840.5$ & 12236.560 \\
& $849.0-850.2$ & 12237.466 \\
& $852.0-853.1$ & 12243.537 \\
\hline
\end{tabular}

of IWV is based on the algorithm SFIT2 (Pougatchev et al., 1995), which is the standard code within the Network for the Detection of Atmospheric Composition Change (NDACC). An FTIR retrieval optimized for IWV was recently developed by Sussmann et al. (2009). In brief, a dedicated set of 3 micro-windows was set up (see Table 1 for detailed information), and by using the water vapor spectroscopy by Toth and coworkers implemented in HITRAN 2000 and HITRAN 2008 (Rothman et al., 2003; Rothman et al., 2009) a spectral fit down to the noise could be achieved for the first time without systematic residuals due to spectroscopic errors (Sussmann and Camy-Peyret, 2002, 2003). As a result the precision of the FTIR retrieval for IWV could be estimated to be better than $0.05 \mathrm{~mm}$ ( $2.2 \%$ of the mean), and perfect matching to the response characteristics of radiosonde-based IWV measurements could be achieved (scatter plot with slope $\equiv 1$ ) by tuning the regularization strengths of a Tikhonov-based spectral inversion scheme applied to the FTIR data; this retrieval has proved its usefulness via a harmonized study of the decadal trends in IWV above the Zugspitze and Jungfraujoch FTIR stations (Sussmann et al., 2009).

\subsection{Differential absorption lidar (DIAL)}

The DIAL method is a laser-based remote sensing technique providing number-density profiles of trace gases. In atmospheric sounding, this method has been applied mainly to ozone and water vapor and benefits from the specific molecular absorption of the trace gas to be measured. The Zugspitze / Schneefernerhaus DIAL system and the retrieval of water vapor profiles are described in more detail by Vogelmann and Trickl (2008). In brief, this DIAL is operated with single absorption lines in the 817-nm band of $\mathrm{H}_{2} \mathrm{O}$ (Table 1) for ground-based water vapor profiling in the free troposphere. Two wavelengths are used, $\lambda_{\text {on }}$ which is placed right in the center of an adequate absorption line and $\lambda_{\text {off }}$ which is nearby, but outside of any line wings, if possible. Both are emitted into the sky in alternating sequence (pulse length $\approx 2 \mathrm{~ns}$, repetition rate $20 \mathrm{~Hz}$ ) with a pulse energy of up to $250 \mathrm{~mJ}$. Their backscatter is collected by a large telescope 
(0.65-m mirror, fixed zenith view) and, after electronic detection, stored in different registers of a transient digitizer (20 MHz, 12 bit). In most cases, the lidar return from the free troposphere is pure Rayleigh backscatter. The watervapor concentration is then retrieved by calculating the differential absorption from the two lidar returns. Geometrical restrictions by the lidar telescope optics do not allow for the detection of water vapor closer than about $185 \mathrm{~m}$ to the lidar. Due to potential imaging artifacts the lower edge of the vertical range is conservatively set to a distance of $275 \mathrm{~m}$ (2950 $\mathrm{m}$ a.s.l.) which is about the altitude of the FTIR instrument (2964 $\mathrm{m}$ a.s.1.). The upper end of the vertical range is normally fixed to $12 \mathrm{~km}$ a.s.l. Here, the sensitivity limit is reached, but still enough lidar return is remaining to keep the noise level low in a reasonable way. A vertical resolution (VDI guideline 4210, 1999) is adapted dynamically (quadratically growing with the distance from the lidar receiver) from about $50 \mathrm{~m}$ to $300 \mathrm{~m}$ within the vertical range. The system yields a narrow-band laser emission $(\leq 220 \mathrm{MHz})$ with a high spectral purity $(>99.9 \%)$ and a high frequency stability $( \pm 35 \mathrm{MHz})$ and, thus, meets the demanding requirements by Bösenberg (1998, Table 4). Narrow-band daylight filtering yields a full daytime measurement capability. The spectral data by Ponsardin and Browell (1997) are used for the calibration because of the successful validation of the line parameters by DIAL measurements (Ferrare et al., 2004). Their reliability is also confirmed by this work.

\subsection{Setup}

Mt. Zugspitze is located on the northern rim of the Alps and by far dominates its surroundings. The site is above or in the upper part of the moist boundary layer during most of the year. This allows for sensitive spectroscopic measurements of water vapor throughout the free troposphere due to reduced absorption losses. As shown in Fig. 1, the FTIR instrument is located on the summit of Mt. Zugspitze at an altitude of $2964 \mathrm{~m}$ a.s.1. The DIAL instrument is located at the Schneefernerhaus research station on the steep southern slope of Mt. Zugspitze at an altitude of $2675 \mathrm{~m}$ a.s.1., $680 \mathrm{~m}$ southwest of the FTIR instrument. This allows for good spatial matching, if FTIR measurements are selected with the solar azimuth angle pointing towards the DIAL location. Furthermore, the DIAL is located $289 \mathrm{~m}$ below the FTIR. This is a very advantageous situation for the intercomparison experiment, because the vertical range of the Zugspitze DIAL starts exactly at the altitude where the FTIR spectrometer is located. For this intercomparison study the upper end of the vertical range of the DIAL was extended from $12 \mathrm{~km}$ to higher altitudes in some cases of an extraordinary high tropopause (e.g., $14 \mathrm{~km}$ on 2 February 2007) or to lower altitudes (down to $9 \mathrm{~km}$ ) in cases of perturbation at altitudes above the point where the sensitivity limit was reached.

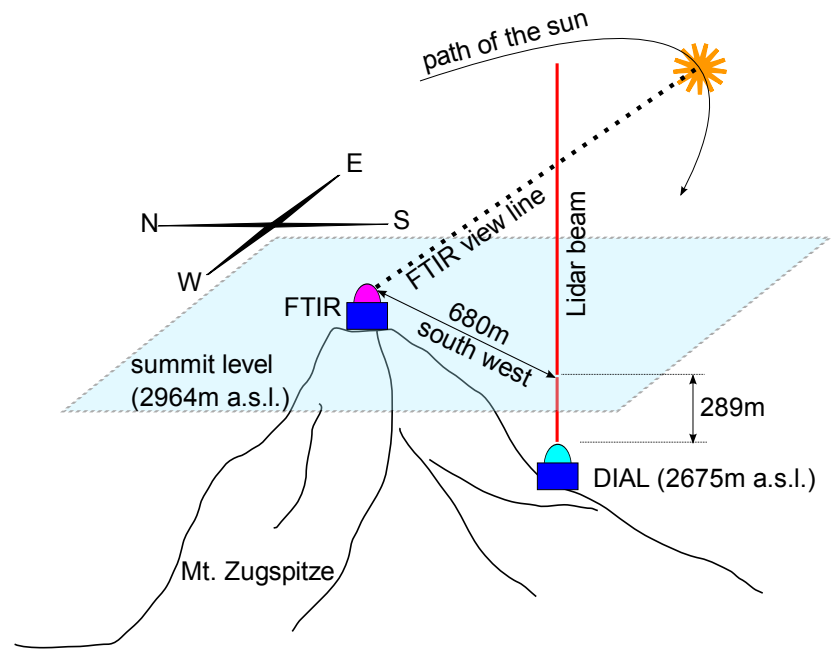

Fig. 1. Collocation of the FTIR and the DIAL on Mt. Zugspitze. The volume matching of the FTIR instrument and the DIAL peaks in the early afternoon at an azimuth of about $210^{\circ}$.

\section{Intercomparison results}

The intercomparison data set comprises 342 lidar profiles from the years 2007-2009. In the same time period 3544 IWV measurements from the solar FTIR instrument were obtained. It was shown by Sussmann et al. (2009) that it is crucial for IWV intercomparison experiments to choose strict temporal matching criteria on a time scale of minutes because of the high variability of IWV. Reducing the temporal coincidence interval of course is a trade-off against the number of available coincident measurement pairs as shown in Fig. 4 of Sussmann et al. (2009). Using a coincidence interval of $22 \mathrm{~min}$ as a starting point we derive a scatter plot with 178 pairs (Fig. 2). The interval length of 22 min yields the smallest standard deviation of differences between DIAL and FTIR IWV values. The pairs are equally distributed over all seasons with an average sun position near equinox. The two sets of pairs in Fig. 2 were obtained from employing two different sets of line parameters in the DIAL retrieval. The grey nodes show the pairs resulting from the HITRAN 2008 dataset (Rothman et al., 2009). The red nodes show the pairs resulting from the dataset of Ponsardin and Browell (1997) which obviously match better the IWV values retrieved from the FTIR, in particular for high IWV values detected with the weak line at $12243.537 \mathrm{~cm}^{-1}$. Two types of outliers had to be eliminated before entering the scatter plot. The first type refers to cases of strongly enhanced backscatter from aerosols leading to an overexposure in the lidar receiver. This was observed during strong Saharan dust events and during heavy winter storms when dust or wind-blown snow from the ground reached the field of view of the receiver optics in the far field channel (typically above $3300 \mathrm{~m}$ a.s.1.). Overexposure can lead to signal-induced nonlinearities over the 


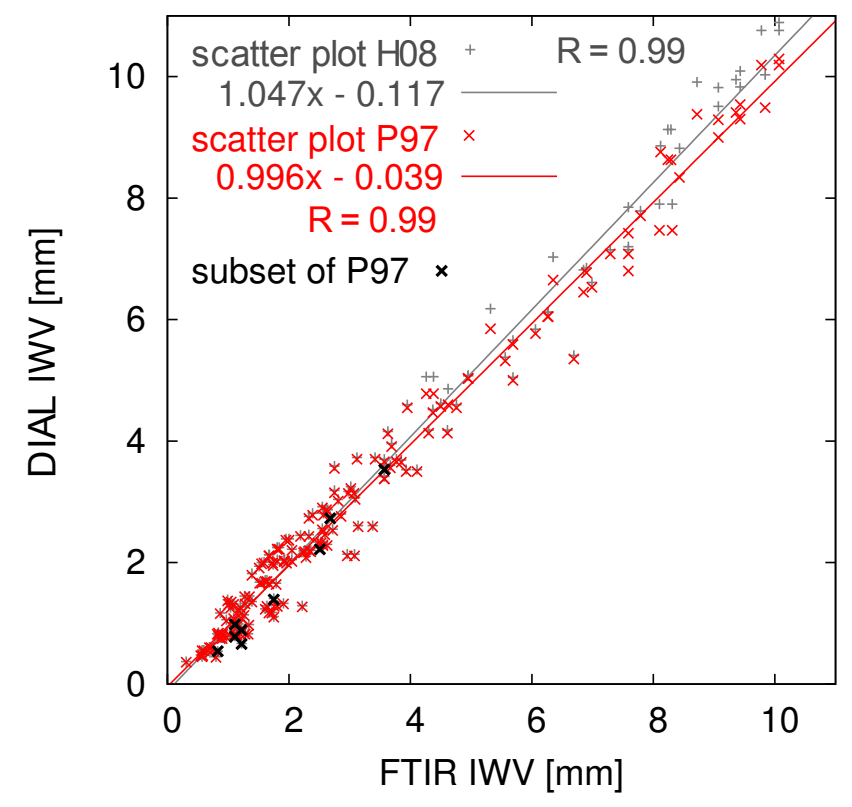

Fig. 2. Scatter plot of FTIR and DIAL measurements for different spectroscopic line parameters used for the water-vapor retrieval of the DIAL. "H08" (grey) is the result if HITRAN 2008 data (Rothman et al., 2009) is used, "P97" (red) is the result if done so with the line parameters from Ponsardin and Browell (1997). For both H08 and P97 pairs of all day times within a coincidence interval of 22 min have been considered. The grey and red lines are correlation lines for "H08" and "P97", respectively. The nodes highlighted with a black cross show a subset of the P97 result which is reduced to pairs within a coincidence interval of $18 \mathrm{~min}$ and an azimuth of $210^{\circ} \pm 6^{\circ}$.

entire measurement range which is mainly produced by the preamplifiers of the transient digitizers. These cases were detected by manually controlling the raw backscatter profiles for signal clipping. The second type refers to cases of strongly perturbed humidity profiles compared to a standard profile with widespread and very dry layers below $4 \mathrm{~km}$ a.s.l. This was observed during stratospheric intrusion events during the winter season. We presume this to be caused by the FTIR retrieval algorithm which cannot resolve vertical structures of the water-vapor profile on small vertical scales below one kilometer. This type of outlier was detected if the DIAL IWV value was greater by more than a factor of two compared to the FTIR IWV value while the visually controlled water vapor profile from the DIAL shows a significant minimum below $4 \mathrm{~km}$ a.s.l. The type-one outlier was detected in 17 cases, the type-two outlier in 9 cases.

\subsection{Bias and slope}

From Fig. 2 we derive bias and slope for two different sets of spectroscopic line parameters in the DIAL retrieval, see Table 2. Briefly, IWV values measured by the DIAL and the
FTIR are highly correlated $(r=0.99$ for both sets of line parameters $)$ as expected from their high variability $(\leq 0.5 \mathrm{~mm}$ to $\geq 10 \mathrm{~mm}$ ). Employing the line parameters of Ponsardin and Browell (1997) leads to a slope of the correlation line which is significantly closer to the optimum value $(\equiv 1)$. The slope is then 0.996 and the intercept $-0.039 \mathrm{~mm}(-1.2 \%$ of the mean). The overall bias is $-0.052 \mathrm{~mm}$ which means a relative bias of $-1.6 \%$ compared to the average IWV of $3.15 \mathrm{~mm}$ above Mt. Zugspitze. The bias is the arithmetic average over all pairwise differences. The negative value means, that the DIAL measures lower column values compared to the FTIR instrument. We assume this is partly caused by the limitation of the measurement range of the DIAL ending at the tropopause, while the FTIR instrument also observes the water vapor in the stratosphere. By using the LOWTRAN-5 mid-latitude atmospheric models (LOWTRAN 5 model, 1989) we know that stratospheric water vapor contributes only about $0.3 \%$ in the summer season and $1.4 \%$ in the winter season to the IWV above Mt. Zugspitze. Note that both FTIR and DIAL slopes and biases found in our study are in very good agreement when keeping the completely different measurement principles in mind (differing retrieval algorithms, differing spectroscopic line parameters). In the following, only the results produced with the parameters of Ponsardin and Browell (1997) will be discussed.

\subsection{Precision}

In order to derive a conservative estimate for the precision of the DIAL for IWV measurements we have to optimize the spatio-temporal matching with the FTIR. The spatial matching varies with daytime because of the sun-pointing observation geometry of the FTIR (Fig. 1). To achieve optimum volume matching of FTIR and DIAL on the scale of $100 \mathrm{~m}$ the azimuth of the FTIR must approximately point to the location of DIAL. For this, a subset of the coincident pairs of Fig. 2 is taken into account, i.e., only pairs with FTIR solar azimuth angles of $210^{\circ} \pm 6^{\circ}$ are used. These pairs are highlighted black in Fig. 2 while the red curve in Fig. 3 shows the standard deviation of the differences between FTIR and DIAL IWV values $\sigma_{\mathrm{I} W V}$ for an azimuth angle of $210^{\circ} \pm 6^{\circ}$ as a function of the coincidence interval. This confirms the results of Sussmann et al. (2009), where two side-by-side FTIRinstruments were intercompared at Jungfraujoch (Switzerland). At Jungfraujoch a standard deviation of $0.07 \mathrm{~mm}$ was obtained for the shortest coincidence intervals, which is of the same order as shown here. As expected, $\sigma_{\mathrm{I} W V}$ is smallest for the shortest temporal coincidence intervals (0.05 mm @ $5 \mathrm{~min})$ and increases with increasing interval length (>0.5 mm @ $1000 \mathrm{~min}$ ).

An extension of the FTIR solar azimuth interval to $210^{\circ} \pm$ $10^{\circ}$ already significantly increases $\sigma_{\mathrm{I} W V}$ for short temporal coincidence intervals as indicated by the upper curve in Fig. 3. This shows, that strict spatial matching on the 100-m scale is required for intercomparison studies of IWV as well 
Table 2. Intercomparison results of DIAL (two sets of line parameters) versus FTIR and FTIR versus FTIR (side-by-side experiment, Sussmann et al., 2009).

\begin{tabular}{|c|c|c|c|c|c|c|}
\hline \multirow[t]{2}{*}{$\begin{array}{l}\text { instruments } \\
\text { DIAL line parameters }\end{array}$} & \multicolumn{2}{|c|}{$\begin{array}{c}\text { DIAL-FTIR } \\
\text { Ponsardin (1997) }\end{array}$} & \multicolumn{2}{|c|}{$\begin{array}{l}\text { DIAL-FTIR } \\
\text { HITRAN } 2008\end{array}$} & \multicolumn{2}{|c|}{$\begin{array}{c}\text { FTIR-FTIR } \\
-\end{array}$} \\
\hline & precision & bias & precision & bias & precision & bias \\
\hline$[\mathrm{mm}]$ & $\leq 0.1$ & $-0.052(26)$ & $\leq 0.1$ & $0.030(28)$ & $\leq 0.05$ & $0.02(1)$ \\
\hline [\% of mean] & $\leq 3.2$ & $-1.6(8)$ & $\leq 3.2$ & $0.9(8)$ & $\leq 2.2$ & $0.96(52)$ \\
\hline slope & $0.996(10)$ & & $1.047(11)$ & & $1.001(7)$ & \\
\hline
\end{tabular}

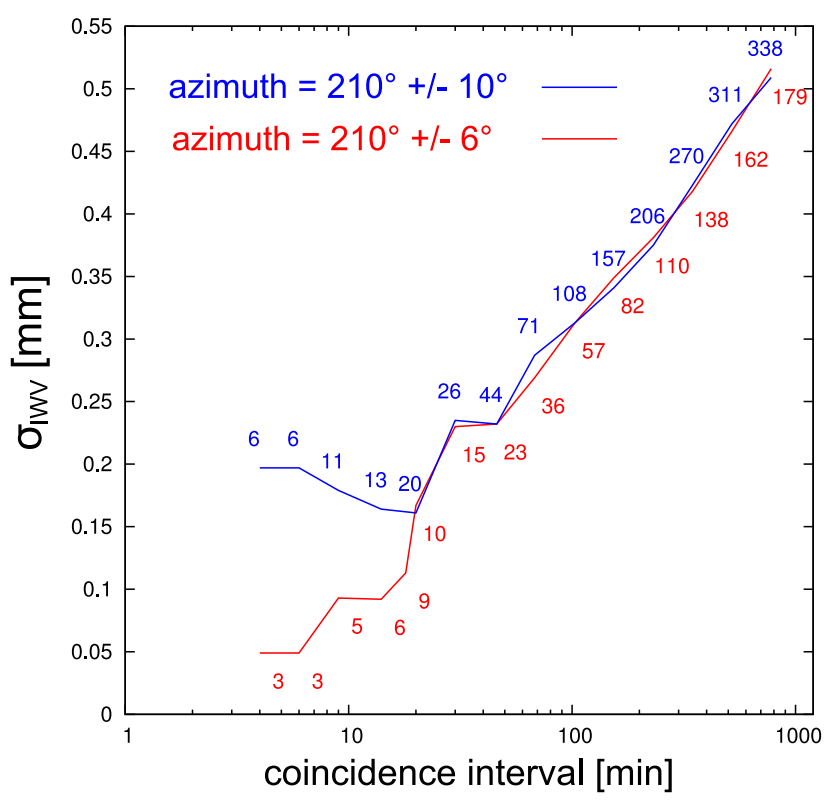

Fig. 3. The standard deviation of differences between DIAL and FTIR IWV values $\sigma_{\text {IWV }}$ as a function of the length of the coincidence interval. Only FTIR measurements within an azimuth interval of $210^{\circ} \pm 6^{\circ}$ were taken into account for the lower curve, while the upper curve is for an increased azimuth interval $\left(210^{\circ} \pm 10^{\circ}\right)$. The numbers of coincident pairs are shown next to both curves.

as strict temporal matching on the 10-min scale, to educe the precision of state-of-the-art IWV sounders.

To estimate the precision of the DIAL, we analyze the standard deviation in the case of optimum volume matching and acceptable temporal matching (see Fig. 3, lower curve). A temporal coincidence interval of $18 \mathrm{~min}$, together with a solar azimuth interval of $210^{\circ} \pm 6^{\circ}$, leads to 9 pairs with a standard deviation of $0.11 \mathrm{~mm}$. Stricter spatio-temporal coincidence criteria yield even smaller standard deviations, but with a statistically insufficient number of pairs. From

$\sigma_{\mathrm{IWV}}=\sqrt{\sigma_{\mathrm{DIAL}}^{2}+\sigma_{\mathrm{FTIR}}^{2}}$

and $\sigma_{\text {FTIR }} \leq 0.05 \mathrm{~mm}$ (Sussmann et al., 2009) we conclude that the precision of the DIAL is better than $0.1 \mathrm{~mm}$. Thus, the DIAL can compete with the upper echelon of water vapor remote sounding techniques.

\section{Summary and outlook}

The intercomparison of FTIR and DIAL IWV measurements produced two major results:

First of all, the slope $(0.996(10))$, correlation $(R=0.99)$ and intercept $(-0.039(42) \mathrm{mm},-1.2 \%$ of the mean) obtained from the DIAL-FTIR scatter plot are almost ideal. The overall bias was found to be $-0.052(26) \mathrm{mm}(-1.6 \%$ of the mean). This is a small value and presumably is partly induced by the limited measurement range of the DIAL, which ends at the tropopause, while the FTIR IWV includes stratospheric water vapor as well. From this, it may be concluded that the absolute value of the effective bias is even smaller than $1.6 \%$. This fact as well as the almost ideal slope $s$ of the correlation line $(s=0.996, R=0.99)$ indicate that the spectroscopic parameters used for the retrieval of both the DIAL and the FTIR instrument are highly consistent. Quantitative spectroscopy of the molecular line parameters was derived independently for FTIR by Toth et al. (1998); Toth (1998, 2000), and, for the DIAL by Ponsardin and Browell (1997), respectively. The agreement (Fig. 2) also reflects the high quality of both retrieval algorithms (Vogelmann and Trickl, 2008; Sussmann et al., 2009).

Secondly, the precision of the DIAL in measuring integrated water vapor was estimated to be better than $0.1 \mathrm{~mm}$ (relative measurement error of $3.2 \%$ ). This value is nearly comparable to the precision of the FTIR $(<0.05 \mathrm{~mm})$ which means that the DIAL is one of the best remote water-vapor sounders in the field of competition (see Table 1 in Sussmann et al., 2009).

Using the diurnally changing spatial overlaps between the solar FTIR and the DIAL we found that a spatial matching on the $100-\mathrm{m}$ scale is required to derive the $(<0.1 \mathrm{~mm})$ precision of state-of-the-art IWV sounders. This complements the finding by Sussmann et al. (2009) that a temporal matching in the order of $10 \mathrm{~min}$ or better is required for the same purpose.

Our goal was to examine the quality of water-vapor measurements with the DIAL from a technical point of view. As a 
side effect, Fig. 3 provided some indications as to the spatiotemporal variability of IWV. In the future, it is planned to derive quantitative information about the three-dimensional field of the spatio-temporal variability of IWV above the Zugspitze by further exploiting the advantageous geometrical arrangement of both instruments with their different observation geometries. This will be the subject of subsequent work.

Acknowledgements. We would like to thank H. P. Schmid (IMKIFU) for his constant interest in this work and are indebted to Markus Rettinger (IMK-IFU) for performing the FTIR measurements.

Funding by the state government of Bavaria (Bayerisches Staatsministerium für Wirtschaft Verkehr und Technologie, contract 3625-VIII/4d-54762) within the DIAL project is gratefully acknowledged as well as the funding by the EC within HYMN (contract 037048) and GEOMON (contract 036677) and the Federal Ministry of Education and Research within ATMOFAST (program AFO 2000).

Edited by: C. Senff

\section{References}

Browell, E. V., Ismail, S., Hall, W. M., Moore, A. S., Kooi, S. A., Brackett, V. G., Clayton, M. B., Barrick, J. D. W., Schmidlin, F. J., Higdon, N. S., Melfi, S. H., and Whiteman, D. N.: LASE validation experiment, in: Advances in Atmospheric Remote Sensing with Lidar, edited by: Ansmann, A., Neuber, R., Rairoux, P., and Wandinger, U., pp. 289-295, Springer-Verlag, selected Papers of the 18th International Laser Radar Conference (ILRC), Berlin, 22-26 July 1996, 1996.

Bruneau, D., Quaglia, P., Flament, C., Meissonnier, M., and Pelon, J.: Airborne lidar LEANDRE II for water-vapor profiling in the troposphere. I. System description, Appl. Opt., 40, 3450-3460, 2001.

Bösenberg, J.: Ground-Based differential absorption lidar for watervapor and temperature profiling: methodology, Appl. Opt., 37, 3845-3860, 1998.

Ehret, G., Kiemle, C., Renger, W., and Simmet, G.: Airborne remote sensing of tropospheric water vapor with a near-infrared differential absorption lidar system, Appl. Opt., 32, 4534-4551, 1993.

Ferrare, R. A., Browell, E. V., Ismail, S., Kooi, S. A., Brasseur, L. H., Brackett, V. G., Clayton, M. B., Barrick, J. D. W., Diskin, G. S., Goldsmith, J. E. M., Lesht, B. M., Podolske, J. R., Sachse, G. W., Schmidlin, F. J., Turner, D. D., Whiteman, D. N., Tobin, D., Miloshevich, L. M., Revercomb, H. E., Demoz, B. B., and di Girolamo, P.: Characterization of Upper-Troposphere Water Vapor Measurements during AFWEX Using LASE, J. Atmos. Ocean Tech., 21, 1790-1808, doi:10.1175/JTECH-1652.1, 2004.

Fiorucci, I., Muscari, G., Bianchi, C., Di Girolamo, P., Esposito, F., Grieco, G., Summa, D., Bianchini, G., Palchetti, L., Cacciani, M., Di Iorio, T., Pavese, G., Cimini, D., and de Zafra, R. L.: Measurements of low amounts of precipitable water vapor by millimeter wave spectroscopy: An intercomparison with radiosonde,
Raman lidar, and Fourier transform infrared data, J. Geophys. Res. Atmos., 113, D14314, doi:10.1029/2008JD009831, 2008.

Harries, J. E.: Atmospheric radiation and atmospheric humidity, Q. J. R. Meteor. Soc., 123, 2173-2186, 1997.

Kiehl, J. T. and Trenberth, K. E.: Earth's Annual Global Mean Energy Budget, B. Am. Meteorol. Soc., 78, 197-208, 1997.

LOWTRAN 5 model: ONTAR Corporation, Address: 9 Village Way, North Andover, MA 01845-2000 USA, 1989.

Morland, J., Deuber, B., Feist, D. G., Martin, L., Nyeki, S., Kämpfer, N., Mätzler, C., Jeannet, P., and Vuilleumier, L.: The STARTWAVE atmospheric water database, Atmos. Chem. Phys., 6, 2039-2056, doi:10.5194/acp-6-2039-2006, 2006.

Pałm, M., Melsheimer, C., Noël, S., Heise, S., Notholt, J., Burrows, J., and Schrems, O.: Integrated water vapor above $\mathrm{Ny}$ Ålesund, Spitsbergen: a multi-sensor intercomparison, Atmos. Chem. Phys., 10, 1215-1226, doi:10.5194/acp-10-1215-2010, 2010.

Ponsardin, P. L. and Browell, E. V.: Measurements of $\mathrm{H}_{2}^{16} \mathrm{O}$ Linestrengths an Air-Induced Broadenings and Shifts in the 815 nm Spectral Region, J. Mol. Spectrosc., 185, 58-70, 1997.

Pougatchev, N. S., Connor, B. J., and Rinsland, C. P.: Infrared measurements of the ozone vertical distribution above Kitt Peak, J. Geophys. Res., 100, 16689-16697, 1995.

Rothman, L. S., Barbe, A., Benner, D. C., Brown, L. R., CamyPeyret, C., Carleer, M. R., Chance, K., Clerbaux, C., Dana, V., Devi, V. M., Fayt, A., Flaud, J. M., Gamache, R. R., Goldman, A., Jacquemart, D., Jucks, K. W., Lafferty, W. J., Mandin, J. Y., Massie, S. T., Nemtchinov, V., Newnham, D. A., Perrin, A., Rinsland, C. P., Schroeder, J., Smith, K. M., Smith, M. A. H., Tang, K., Toth, R. A., Vander Auwera, J., Varanasi, P., and Yoshino, K.: The HITRAN molecular spectroscopic database, edition of 2000 including updates through 2001, J. Quant. Spectrosc. Radiat. Transfer, 82, 5-44, 2003.

Rothman, L. S., Gordon, I. E., Barbe, A., Benner, D. C., Bernath, P. F., Birk, M., Boudon, V., Brown, L. R., Campargue, A., Champion, J., Chance, K., Coudert, L. H., Dana, V., Devi, V. M., Fally, S., Flaud, J., Gamache, R. R., Goldman, A., Jacquemart, D., Kleiner, I., Lacome, N., Lafferty, W. J., Mandin, J., Massie, S. T., Mikhailenko, S. N., Miller, C. E., MoazzenAhmadi, N., Naumenko, O. V., Nikitin, A. V., Orphal, J., Perevalov, V. I., Perrin, A., Predoi-Cross, A., Rinsland, C. P., Rotger, M., Šimečková, M., Smith, M. A. H., Sung, K., Tashkun, S. A., Tennyson, J., Toth, R. A., Vandaele, A. C., and Vander Auwera, J.: The HITRAN 2008 molecular spectroscopic database, J. Quant. Spectrosc. Radiat. Transfer, 110, 533-572, doi:10.1016/j.jqsrt.2009.02.013, 2009.

Schermaul, R., Learner, R. C. M., Newnham, D. A., Williams, R. G., Ballard, J., Zobov, N. F., Belmiloud, D., and Tennyson, J.: The Water Vapor Spectrum in the Region 8600-15 $000 \mathrm{~cm}^{-1}$ : Experimental and Theoretical Studies for a New Spectral Line DatabaseI. Laboratory Measurements, J. Mol. Spectrosc., 208, 32-42, doi:10.1006/jmsp.2001.8373, 2001.

Schneider, M. and Hase, F.: Ground-based FTIR water vapour profile analyses, Atmos. Meas. Tech., 2, 609-619, doi:10.5194/amt2-609-2009, 2009.

Schneider, M., Romero, P. M., Hase, F., Blumenstock, T., Cuevas, E., and Ramos, R.: Continuous quality assessment of atmospheric water vapour measurement techniques: FTIR, Cimel, MFRSR, GPS, and Vaisala RS92, Atmos. Meas. Tech., 3, 323 
338, doi:10.5194/amt-3-323-2010, 2010.

Sussmann, R. and Camy-Peyret, C.: Ground-Truthing Center Zugspitze, Germany for AIRS/IASI Validation, Phase I Report, Tech. rep., EUMETSAT, http://www.imk-ifu.kit.edu/downloads/ AIRSVAL_Phase_I_Report.pdf, last access: May 2011, 2002.

Sussmann, R. and Camy-Peyret, C.: Ground-Truthing Center Zugspitze, Germany for AIRS/IASI Validation, Phase II Report, Tech. rep., EUMETSAT, http://www.imk-ifu.kit.edu/downloads/ AIRSVAL_Phase_II_Report.pdf, last access: May 2011, 2003.

Sussmann, R. and Schäfer, K.: Infrared spectroscopy of tropospheric trace gases: combined analysis of horizontal and vertical column abundances, Appl. Opt., 36, 735-741, 1997.

Sussmann, R., Borsdorff, T., Rettinger, M., Camy-Peyret, C., Demoulin, P., Duchatelet, P., Mahieu, E., and Servais, C.: Technical Note: Harmonized retrieval of column-integrated atmospheric water vapor from the FTIR network - first examples for longterm records and station trends, Atmos. Chem. Phys., 9, 89878999, doi:10.5194/acp-9-8987-2009, 2009.

Tolchenov, R. and Tennyson, J.: Water line parameters from refitted spectra constrained by empirical upper state levels: Study of the 9500-14500 $\mathrm{cm}^{-1}$ region, J. Quant. Spectrosc. Radiat. Transfer, 109, 559-568, doi:10.1016/j.jqst.2007.08.001, 2008.

Toth, R.: Water Vapor Measurements between 590 and $2582 \mathrm{~cm}^{-1}$ : Line Positions and Strengths, J. Mol. Spectros., 190, 379-396, doi:10.1006/jmsp.1998.7611, 1998.

Toth, R. A.: Air- and $\mathrm{N}_{2}$-Broadening Parameters of Water Vapor: 604 to $2271 \mathrm{~cm}^{-1}$, J. Mol. Spectrosc., 201, 218-243, doi:10.1006/jmsp.2000.8098, 2000.
Toth, R. A., Brown, L. R., and Plymate, C.: Self-broadened widths and frequency shifts of water vapor lines between 590 and $2400 \mathrm{~cm}^{-1}$., J. Quant. Spectrosc. Radiat. Transfer, 59, 529-562, doi:10.1016/S0022-4073(97)00144-1, 1998.

Trenberth, K., Jones, P., Ambenje, P., Bojariu, R., Easterling, D., Tank, A., Parker, D., Rahimzadeh, F., Renwick, J., Rusticucci, M., Soden, B., and Zhai, P.: Observations: Surface and Atmospheric Climate Change. In Climate Change 2007: The Physical Science Basis. Contribution of Working Group I to the Fourth Assessment Report of the Intergovernmental Panel on Climate Change, chap. 3, pp. 235-336, Cambridge, United Kingdom and New York, N.Y., USA, Cambridge University Press, 2007.

VDI guideline 4210: Remote sensing, Atmospheric measurements with LIDAR, Measuring gaseous air pollution with the DAS LIDAR, Verein Deutscher Ingenieure, Beuth Verlag, Berlin, 47 pp., 1999.

Vogelmann, H. and Trickl, T.: Wide Range Sounding of Free Tropospheric Water Vapor with a Differential Absorption Lidar (DIAL) at a High Altitude Station, Appl. Opt., 47, 2116-2132, 2008.

Wirth, M., Fix, A., Ehret, G., Reichardt, J., Begie, R., Engelbart, D., Vömel, H., Calpini, B., Romanens, G., Apituley, A., Wilson, K. M., Vogelmann, H., and Trickl, T.: Intercomparison of Airborne Water Vapour DIAL Measurements with Ground Based Remote Sensing and Radiosondes within the Framework of LUAMI 2008, in: Proceedings of the 8th International Symposium on Tropospheric Profiling, edited by: Apituley, A., Russchenberg, H. W. J., and Delft, W. M., The Netherlands, 2009. 